\title{
Pensar desde otro lugar, pensar lo impensable: hacia una pedagogía queer
}

Gracia Trujillo'

\section{Resumen}

El reconocimiento de la diversidad ha asumido un papel crucial en lo que respecta a la educación debido a las transformaciones sociales que han tenido lugar en las llamadas democracias avanzadas. Ciertamente, el contexto multicultural y la preeminencia de las luchas por el reconocimiento de las diferencias (ya sean sexuales, de género(s), raciales, culturales, religiosas, etc.) son las dos características principales que podrían caracterizar las tendencias sociales actuales. No obstante, las diferentes concepciones de la diversidad, implícitas y no suficientemente cuestionadas, delimitan un área controvertida de debate. Teniendo en cuenta estas consideraciones, mi objetivo en este artículo es, por una parte, realizar una reflexión crítica sobre los límites y los retos que la diversidad de género y sexual representa en el ámbito educativo, y para la política actual; y, por otra, analizar las aportaciones que desde las teorías feministas y queer se vienen realizado en los últimos años y su valiosa contribución para la educación. El artículo concluye con unas notas sobre la(s) pedagogía(s) queer y los retos que plantean.

\section{Palabras clave}

Educación - Heteronormatividad - Diversidad - Feminismos queer.

I- Universidad de Castilla- La Mancha,

España.

Contacto: Gracia.Trujillo@uclm.es 


\title{
Thinking from another place, thinking the unthinkable: towards a queer pedagogy
}

Gracia Trujillo

\begin{abstract}
The recognition of diversity has assumed a crucial role with regards to education due to the social transformations that have been taking place in the so-called advanced democracies. Indeed, the multicultural context and the preeminence of the struggles for recognition of (sexual, gender, racial, cultural, religious, or other) differences are the two main characteristics of current social trends. However, the different implicit and insufficiently questioned conceptions of diversity delineate a controversial area of debate. With these considerations in mind, my aim in this article is, on the one hand, to make a critical reflection on the limits and challenges that sexual and gender diversity poses to the educational sphere, and to current politics; and, on the other, to analyze the valuable contributions drawn from feminist and queer theories and their importance to education in recent years. The article concludes with some notes on queer pedagogy and its challenges.
\end{abstract}

\section{Keywords}

Education - Heteronormativity - Diversity - Queer feminisms.

I- Universidad de Castilla- La Mancha,

España.

Contact: Gracia.Trujillo@uclm.es 


\section{Introducción}

Hace unos meses, en una de mis clases de Sociología de la Educación, asignatura del Grado de Maestro/a de Educación Infantil, les puse a mis alumnas el video Vestido nuevo (y digo alumnas, entre otras razones porque todos los años son el 98 o 99\% de mi clase, altamente feminizada; esta es otra cuestión que precisamente les propongo a ellas analizar durante el curso) ${ }^{1}$. Este corto (dura 14 minutos) es la historia de un niño, de alrededor de seis años, que va al colegio un día con un vestido (rosa) de su hermana. Es el día de carnaval y de él se espera que lleve un disfraz de dálmata, como el resto de la clase, para la fiesta que va a haber por la tarde. Mario, así se llama el protagonista, va al colegio ya desde por la mañana con otro disfraz (a fin de cuentas, la manera en la que nos vestimos es nuestra forma de mostrarnos al mundo, nuestra especie de disfraz). Al entrar y sentarse en su mesa se hace el silencio en el aula. La maestra, joven, le pregunta, en tono inquisitivo, nada más verle: "Mario, ¿qué estás haciendo?”. El chaval no contesta. Y ella entonces le dice, como aclarándole a la clase: "vas vestido de niña". Otro alumno, sentado al final, le insulta: "maricón". La maestra se lleva a Mario del aula al despacho del Director del centro. Cuando éste le pregunta a la profesora por qué va el niño vestido así, ésta al final acaba respondiendo que "la verdad es que no parece pasarle nada", a lo que el Director le ordena que cambie al niño y que él hablará con su padre. Acto seguido aparece éste a llevarse a Mario, y lo primero que le inquiere es que qué hace con la ropa de su hermana. El Director trata de aclarar con el padre la "confusión": el centro ya había avisado a las familias de que el carnaval era por la tarde. En ese momento, se ve a la maestra, que está recogiendo la mochila de Mario de la clase y ve que dentro está el disfraz de dálmata. Mario no está confundido. Mientras tanto, el padre, medio molesto con las preguntas del

1- El video está disponible on line en el siguiente enlace: http://www. youtube.com/watch?v=JMakydi0p7o\&feature $=\mathrm{kp}$
Director, le acaba diciendo que "viene de niña porque le gusta disfrazarse". Mario espera fuera, acompañado de otra alumna, que es su amiga y que le dice que no se puede vestir de niña, que eso es "ilegal". Lo han hecho en la casa de ella, y pintarse las uñas de colores, pero todo eso fuera no se puede. Al final, el padre acaba llevándose al chaval del cole, cubriéndole con su chaqueta de traje, en una mezcla de gesto cariñoso y avergonzado. Y problema resuelto.

El corto da para comentar infinidad de cosas, entre otras el fracaso colectivo de varios adultos, que representan al colegio y a la familia, ante Mario. Pero me llamó la atención, cuando lo revisaba en casa preparando la clase, algunos de los comentarios que había dejado la gente en youtube que hacían referencia a qué bien estaba tratado el tema de la homosexualidad, qué difícil ser transexual en la escuela, etc. Cuando pregunté a mi clase, alrededor de setenta chicas y tres chicos, qué nos contaba el video, las respuestas fueron, como era de esperar, en esta línea. Aproveché para queerizar el tema: no, no sabemos si es homosexual o no. Tampoco si es transexual. ¿En qué momento Mario dice algo así? La historia sólo nos cuenta que va al colegio con un vestido de su hermana porque le gustan las "cosas bonitas", como explica él. ¿Y qué hubiera pasado, por cierto, si hubiera llevado el vestido para ponérselo por la tarde? ¿En la fiesta de carnaval le habrían dejado en paz, si se hubiera leído el vestido como lo que es, un disfraz? Vuelvo a la cuestión que me parece central: no sabemos más de sus gustos sexuales, de cómo se definiría, si tuviera que hacerlo (itiene seis años!). No nos está descubriendo su identidad, de género o sexual, que hemos deducido ya rápidamente que no es normal porque lleva un vestido rosa. Pero, ¿por qué necesitamos meterle rápidamente en una caja o en dos? Ah, es transexual. 0 es gay. Pero bueno, en todo caso algo raro le pasa, si lleva un vestido de su hermana. ¿Cómo es que un trozo de tela crea este lío que nos cuenta el video? ¡Esto sí que es un arma de 
destrucción masiva!, les digo, bromeando. Pero, ¿el problema es Mario o es la escuela? Aquí ya creo que no saben muy bien ni qué contestarme. Y soy consciente, mientras les hago estas preguntas, que les estoy provocando más dudas que certezas, que no les estoy explicando las definiciones de homosexual, transexual, transgénero, cisexual, como tal vez esperarían, para que copien unas líneas en su cuaderno. Estoy segura de que más de uno y una están pensando que el vídeo trata sobre la homosexualidad porque su profesora muy heterosexual no parece, y habla de estas cosas en clase: nos va a llevar por ahí, pueden intuir. Y estoy, una vez más, dando un salto sin red. Tengo comprobado con algunos alumnos y alumnas, después de llevar ya unos años en esta Facultad, que pueden hacer la carrera entera de Educación y no oír hablar de bullying, por ejemplo. Y van a ser maestrxs de Infantil y de Primaria. Si ya siendo docentes tenemos una gran responsabilidad a muchos niveles con nuestro alumnado, en este caso, formando a futuros formadorxs, la responsabilidad es doble. En general no se suelen tratar estas cuestiones de géneros y sexualidades en los cursos de Grado, no hay asignaturas de libre elección sobre estos temas; en mi Facultad, todo lo más que conocen, o pueden llegar a conocer, es a través de jornadas o cursos, que he ido organizando -o alguna otra profesora, más centrada en cuestiones de género- en plan voluntarista. No es mi intención aquí tanto hablar de mí (y mis méritos) sino desde mi experiencia como docente que habla de sexualidades en un contexto nada queer y bastante hostil, todavía hoy, a estas temáticas. $\mathrm{Y}$ es que, pese a todo, no podemos ni debemos dejar de hacerlo, desde un punto de vista ético $\mathrm{y}$ pensando en nuestro alumnado (y en el futuro al que ellxs darán clase).

Sin embargo, ¿cómo puedo yo pensar en queerizar mis maneras de dar la clase, los contenidos, el lenguaje, la propia clase, en un contexto tan poco queer? ¿Es posible, si no hay unos estudios de género, de sexualidad,
$\mathrm{LGTBI}^{2}$ previos? ¿Por qué no es suficiente el discurso de la diversidad en la escuela, qué límites e implicaciones tiene? ¿Cómo acercar no sólo mis conocimientos, lecturas, reflexiones, investigaciones sobre teorías y prácticas feministas y queer sino mi experiencia activista en grupos feministas, de lesbianas y queer de casi dos décadas (que continúa a día de hoy)dos ámbitos que no puedo ni quiero desligar- a mi labor como docente? ¿Podemos pensar en una(s) pedagogía(s) queer? ¿Cómo hablar de sexualidad, e intentar hacerlo de otra manera, escapar del pensamiento straight (e identitario) y no perder tu trabajo, en un contexto en el que los docentes estamos -seguimos estando- muy solxs con estos temas, mientras la universidad pública está sufriendo unos ataques sin precedentes que se reflejan, entre otras cosas, en los recortes, los despidos, la precarización, todavía más, de la enseñanza? ¿Cómo pensar desde otro lugar en este contexto sin desfallecer en el intento? Estas son, entre otras cuestiones, las que me gustaría analizar en este texto.

\section{Cuerpos y deseos abyectos en el ámbito educativo}

Después de ver Vestido nuevo, lo que yo le sugiero a mi clase es que no nos están hablando de ningún descubrimiento de una identidad homosexual, sino tan sólo de un niño que se enfrenta a una serie de hostilidades por llevar una ropa que no es la esperada de su género (esta es mi lectura queer, una de las posibles). Y les invito a girar el foco de análisis de Mario a la escuela, al contexto que le rodea. Entrecomillo homosexual para subrayar que es una categoría creada por la medicina en el siglo XIX, como explica Foucault en su Historia de la sexualidad (1978). Y siguiendo este hilo, les sorprendo explicándoles cómo la homosexualidad y la heterosexualidad son construcciones culturales, y que la categoría que englobaba un conjunto de desviaciones (la homosexualidad) se

2- Lesbianas, gays, transexuales, bisexuales e intersexuales. 
inventó antes que la respetable y normal (la heterosexualidad). Ambas tienen una historia, idea desnaturalizadora que siempre me ha parecido muy buena para comenzar a hablar de estas cuestiones en el Grado e incluso en los cursos de Postgrado en mi universidad y en otras, que es donde enseño, aquí sí, cuestiones de Sociología del género y la sexualidad, activismos y teorías feministas y queer, etc. ${ }^{3}$ Las identidades son, por tanto, una construcción histórica y social, elementos contingentes, maleables, no homogéneos ni fijos: no son esencias. Y, siguiendo con Foucault (1978), están atravesadas por relaciones de poder.

La escuela (utilizo este término a lo largo del texto para referirme al sistema educativo) es un espacio de socialización clave, y es fundamental, junto con los medios de comunicación, en la construcción de las subjetividades. Como apunta Ferrari (2011, p. 1):

(...) conocer y controlar los deseos, las emociones, los pensamientos y las acciones pasaron a imponerse a cada uno como forma de autoconocimiento y necesidad de construir y decir, por lo menos a uno mismo, las "verdades" personales.

Uno de los vectores clave en esa construcción de las subjetividades es la sexualidad; aunque no se suela considerar así, las identidades sexuales son algo relevante para todo el alumnado (y profesorado), no sólo el no heterosexual. La heterosexualidad ha sido históricamente construida como la sexualidad natural, legítima, respetable, legal, visible, y la masculinidad hegemónica (heterosexual) se enseña y construye en oposición al otro, o la otra, el diferente: las mujeres y los gays. Estos

3- En la actualidad no hay cursos de Postgrado en mi Facultad, que se encuentra en plena transición de Escuela de magisterio (donde se obtenía una diplomatura, después de tres años), a Facultad (Grados de cuatro años), en el marco del Plan de Bolonia, cuyo objetivo era homologar las carreras a nivel europeo. En mi universidad, el espacio donde incluyo, de manera transversal, estos contenidos es en el Máster de igualdad, y en el máster de formación del profesorado de educación secundaria, pero no están institucionalizados como tal (no hay un Grado o un departamento dedicado a estos temas). son algunos de los valores que se (re)producen en la escuela: la heterosexualidad obligatoria, la misoginia, el sexismo, el racismo, la homofobia. $\mathrm{Y}$, al mismo tiempo, la escuela es un ámbito privilegiado para prevenirlos (TRUJILLO, 2011).

El ámbito educativo es un espacio que rechaza y violenta, todavía hoy, al alumnado diferente. Pensando en las sexualidades, la escuela es una auténtica máquina del régimen heteronormativo. Warner describe la heteronormatividad como

(...) los procesos normalizadores que mantienen la heterosexualidad como la forma elemental de asociación humana, como el modelo de las relaciones entre los géneros, como la base indivisible de toda comunidad y como los medios de reproducción sin los cuales la sociedad no existiría ${ }^{4}$ (WARNER, 1993, p. xxi).

En educación, como en el resto de ámbitos, opera la presunción de heterosexualidad para todo el mundo: alumnado, profesorado, y familias de ambos. Así, se empuja a las personas no heterosexuales a tener que salir del armario, a hablar de sexualidad, como diría Weeks (1992), si queremos no tener que inventarnos una vida paralela o dar la sensación de que hay algo que ocultar; la otra opción es permanecer en el silencio (el famoso no preguntes, no digas). Esta lógica nos sitúa en el terreno de la excepcionalidad, como un caso exótico, diferente, a descubrir o, peor todavía, que puede ser revelado, con intenciones no precisamente agradables, por alguien que cree conocer tu secreto. La sexualidad (y la homofobia), queda circunscrita, de esta manera, a una cuestión individual, cuando sabemos que, muy al contrario, no es algo solamente personal sino que tiene una dimensión social y política (LOURO, 2000).

Sin embargo, la educación no habla, en general, del cuerpo ni de sus placeres, como

4- Traducción mía del original en inglés. 
tampoco lo hace la Filosofía o las Ciencias Sociales. Como apunta Moita

(...) en la clase entran cuerpos que no tienen deseo, que no piensan en sexo o que son, especialmente, desexualizados para entrar en ese recinto, como si el cuerpo y la mente existieran aisladamente uno del otro o como si los significados, constitutivos de lo que somos, aprendemos y sabemos, existiesen de forma separada de nuestros deseos. $(2008 \text {, p. 126) })^{5}$.

Y lo mismo podemos decir de los cuerpos de profesorxs, que "son construidos como si no tuviesen deseo sexual” (2008, p. 126). No sólo eso, de nuevo, la presunción de heterosexualidad opera como con el alumnado. El cuerpo es como un texto, algo aplicable a todos los docentes. En mi caso, lo que se puede leer es que soy una profesora rara (queer), no llevo faldas ni maquillaje ni el pelo largo ni tacones ni hablo de un marido o un novio, en fin, no es difícil deducir que no soy heterosexual. Mi aspecto no femenino 6 es, en el espacio de la clase, un gesto activista en sí (y a este respecto siempre pienso en el trabajo tan inspirador de bell hooks, Teaching to transgress: education as the practice of freedom).

En la escuela, además, hay diversos cuerpos y deseos no heteronormativos, abyectos, impensables, invivibles (BUTLER, 2002); entre estos últimos, los cuerpos trans no sólo sufren más violencias que otros, sino que muestran cómo la propia construcción del género como algo binario es ya en sí misma una violencia que genera múltiples exclusiones. Nuestros cuerpos están atravesados y marcados, asimismo, por otros factores como la clase social, el color de la piel, la edad, la cultura. Como señala Moita, el proceso de olvidar los cuerpos naturaliza los

$\mathbf{5}$ - Traducción mía del original en portugués.

$\mathbf{6}$ - valeria flores ha escrito sobre esta cuestión de los cuerpos y deseos inapropiados en el ámbito educativo. Véase, entre otros muchos textos interesantes, "El armario de la maestra tortillera. Políticas corporales y sexuales en la enseñanza", disponible en su blog: http://escritoshereticos. blogspot.pt/2009/07/el-armario-de-la-maestra-tortillera.html. ideales corporales de raza como blanquitud, de género como masculinidad, y de sexualidad como heterosexualidad (2008: 126). Ese eclipsamiento del cuerpo no quiere decir, sin embargo, que la escuela no produzca identidades corporizadas: se trata de una de las instancias principales de reproducción, producción $\mathrm{y}$ organización de las identidades sociales de forma generizada, sexualizada y racializada (LOURO, 1997; MOITA, 2008). El sistema educativo (re)produce la heteronormatividad (y el sexismo, y el racismo), a través de los discursos y las prácticas que fabrican sujetos e identidades, aunque también hay experiencias y prácticas de agencia y resistencia de los sujetos. En definitiva, la escuela es una institución heterosexual, heteronormativa y heteronormalizadora (WARNER, 1993). De ahí la necesidad urgente de continuar haciendo un trabajo crítico y de seguir deconstruyendo los discursos y los silencios desde los ciclos iniciales de la educación (Infantil); después empieza a ser tarde, como muestra el video comentado al comienzo, en el que un niño de seis años ya le insulta a otro maricón ${ }^{7}$. La productividad de las teorizaciones queer reside, de hecho, en este doble impulso de producción y desconstrucción. Como apunta Borrillo, "como la xenofobia, el racismo o el antisemitismo, la homofobia es una manifestación arbitraria que consiste en señalar al otro como contrario, inferior o anormal" (2001, p. 13). Los espacios educativos, y el profesorado, deben contar con herramientas para prevenir y evitar las desigualdades, las discriminaciones y las diferentes formas de violencias (verbales $\mathrm{y}$ físicas) existentes hacia el alumnado diferente. En la construcción de las subjetividades de nuestro alumnado queer, el rechazo, los silencios e invisibilidades, y las imágenes y etiquetas negativas tienen un impacto brutal, como lo tiene el miedo constante a la injuria, del que habla Eribon (2001). No obstante, en

7- A este respecto, véase el trabajo pionero de Sánchez Saiz dedicado a la Educación Infantil (2010) y el relativo a la Educación Secundaria Obligatoria (2009). 
los cuerpos y sujetos marcados existe, como explica Butler (2002), la posibilidad de la resignificación del insulto: ¿maricón yo? Anda, ipues claro, y mira tú qué bien! (aunque para que Mario respondiera esto o algo por el estilo habría que darle un margen de unos años).

\section{Los discursos de la diversidad:} límites e implicaciones

La introducción de cuestiones relativas a la clase social, el género, la etnicidad, la raza o la diversidad funcional en educación no ha sido una tarea fácil sino un proceso largo y complejo en el que hay que incluir a las movilizaciones sociales, las negociaciones en el ámbito político, la implementación de políticas públicas y las recomendaciones europeas, entre otros factores. Así, estos temas han ido siendo incluidos, con mayor o menor rapidez y éxito, en nuestros planes educativos; las intenciones eran buenas, pero, como defenderé más adelante, la inclusión no es suficiente. Deberíamos analizar en qué términos el género y la sexualidad han sido y están siendo actualmente añadidos al sistema educativo (o suprimidos de él, en el contexto político español actual) y qué estereotipos se pueden estar reforzando. Concluyo esta sección del artículo con una breve reflexión sobre qué límites e implicaciones tienen estas nociones (liberales) de diversidad y reconocimiento de las diferencias.

En el contexto del Estado español, fue a partir de los años noventa cuando las organizaciones políticas LGTB y queer comenzaron a llamar la atención sobre cuestiones tales como la falta de educación sexual y la existencia de actitudes homófobas (y sexistas y xenófobas) en las escuelas, con diferentes planteamientos (más de carácter asistencial en el caso de los colectivos LGTB de corte identitario, y de crítica radical en los grupos queer). Ha habido, en España, dos leyes importantes con respecto a la inclusión de la diversidad en la educación, ambas aprobadas con el Partido Socialista (PSOE) en el Gobierno: la LOGSE, Ley de Ordenación General de Sistema Educativo (1/1990), que incorporó cuestiones relacionadas con la atención a la diversidad por primera vez en nuestro sistema educativo y la LOE, la Ley Orgánica de Educación (2/ 2006), que contemplaba la diversidad afectivo-sexual del alumnado y de sus familias, e introdujo la asignatura de Educación para la ciudadanía, diseñada para los niveles de primaria y secundaria a raíz de una recomendación del Consejo Europeo. La idea, como se defendió entonces, era enseñar esta materia e incluir las cuestiones de diversidad en el curriculum de manera transversal en todas las asignaturas, ciencias incluidas. Actualmente, la reciente ley aprobada por el conservador Partido Popular (PP), la LOMCE, la Ley Orgánica para la Mejora de la Calidad Educativa (2013) ha suprimido esta asignatura del curriculum escolar, y toda mención a la diversidad sexual (y funcional, cultural, corporal). La única alusión a la diversidad que aparece en la ley es la referida a los estudiantes con problemas de rendimiento.

En la LOE se hacía, por primera vez, referencia explícita a la diversidad sexual en el ámbito educativo. Esta ley, en su preámbulo, concretaba lo siguiente:

Entre los fines de la educación se resaltan el pleno desarrollo de la personalidad y de las capacidades afectivas del alumnado, la formación en el respeto de los derechos y libertades fundamentales y de la igualdad efectiva de oportunidades entre hombres y mujeres, el reconocimiento de la diversidad afectivo-sexual, así como la valoración crítica de las desigualdades que permita superar los comportamientos sexistas. (ESPAÑA, 2006, p. 7).

Se hacía necesario, por tanto, incluir formas de actuación que tuvieran en cuenta la diversidad afectivo-sexual del alumnado y de sus familias. También en la LOE se establecía en su artículo 91 que “se reconocerá la labor didáctica del profesorado que atienda al desarrollo 
afectivo del alumnado y que contribuya al respeto, la tolerancia y la libertad" (p. 58). Asimismo, su artículo 102 aludía a la necesidad de formación permanente de los docentes: si estxs docentes no están formados de cara a una realidad educativa compleja, difícilmente podían continuar en la línea de hacer de esa escuela un espacio más inclusivo. La diversidad sexual estaba, por tanto, incluida en la ley (lo que, a efectos prácticos, supuso blindar a los profesores/as que incluían estos temas en sus aulas frente a posibles críticas o malas reacciones de los centros y las familias de los alumnos). El argumento aquí era que, como he mencionado más arriba, deben tratarse en la escuela, que es un espacio privilegiado para analizar, combatir y prevenir las discriminaciones, pero no es un lugar libre de ellas. Sin embargo, a mi modo de ver, la inclusión constituye solamente una primera fase, y necesitamos analizar la forma en que estas cuestiones se están considerando, sus límites, y la lógica política que está detrás de ella.

$\mathrm{Al}$ analizar la incorporación del género y la diversidad sexual en el sistema educativo, una de las primeras cosas que convendría hacer es referirnos a las diversidades de géneros y de sexualidades, en plural, ya que son múltiples. Es necesario analizar las complejas relaciones entre ambos, y, al mismo tiempo, estudiarlos por separado, como Gayle Rubin (1984), entre otras teóricas feministas y queer sugirió ya en los años ochenta: tienen elementos comunes, pero también diferencias en cuanto a las discriminaciones y la forma en que éstas se pueden experimentar. Hay además numerosas cuestiones que estudiar en torno al control y la vigilancia de las mismas desde diversas instancias (entre ellas la escuela). En el discurso de la diversidad, se echa de menos una perspectiva interseccional al analizar géneros y sexualidades y cómo están atravesados por otras variables como la clase o la raza, como mostré en la sección anterior.

Por otra parte, la diversidad sexual parece, en general, no escapar a la lógica binaria: el género entendido como hombre versus mujer, y como sinónimo de sexo. De esta manera, el potencial crítico de la categoría género es desactivado, al tiempo que se refuerzan las conexiones naturalizadas entre el sexo, el género, la opción sexual, la identidad de género, etc. Lo mismo sucede con la multiculturalidad: al sumar un vector de opresión a otro (soy una persona de clase media y blanca y mujer y...) se corre el riesgo de terminar convirtiendo las identidades en elementos esenciales y no contingentes una vez más, y de reproducir los estereotipos. En otras palabras, la interseccionalidad leída de esta manera estaría reforzando el discurso y las nociones de representación y ciudadanía liberales, no las radicales. Como apunta Rofes (2005, p. 145).

[...] fundamentalmente, se trata de una cuestión de participación democrática en la esfera pública. Cuando decimos que "valoramos la diversidad", ¿nos referimos a que creamos lugares donde las personas de diferente género, raza, clase e identidad sexual pueden juntarse y traer consigo los atributos sociales $y$ culturales que los definen como diferentes, inusuales, transgresivos? ¿0 queremos decir que nos gusta la idea de la diversidad pero, en la práctica, tendemos a encubrir, silenciar, desexualizar, enderezar e ignorar las diferencias culturales? ${ }^{8}$

Las cuestiones de diversidad incluidas en los planes educativos suelen responder asimismo a una matriz heterosexual y blanca. La raza se incluye, la mayoría de las veces, como algo exótico que debemos tolerar, más que como diferentes formas culturales que hay que respetar. Y esto no es una cuestión superficial: el sistema educativo, como veíamos anteriormente, es uno de los principales ámbitos que tenemos que tener en cuenta al analizar las configuraciones identitarias. La escuela es un

8 - El subrayado aparece en el original. 
agente de socialización clave y es central en cuanto a la transmisión de los roles, expectativas, modelos. Estamos manejando aquí una serie de diferencias reguladas, junto con una constelación de voces no articuladas, excluidas; se hace necesario, por tanto, superar los límites y las fronteras de un discurso de la diversidad normalizada y trabajar en la defensa de la legitimidad y el respeto a las diferentes diferencias.

En esta línea, no parece suficiente añadir contenidos sobre gays y lesbianas al curriculum de diversidad multicultural. El argumento aquí es que la ausencia de representaciones tiene efectos negativos, injuriosos, y su inclusión es el remedio contra la homofobia y el prerrequisito para la autoestima y la existencia segura del alumnado LGTBI en la clase. Sin negar la importancia de esos efectos negativos, sino todo lo contrario, creo que debemos considerar cómo la homo-lesbo-transfobia se presenta así como un problema de representación, un efecto de la ausencia de imágenes de personas trans, lesbianas y gays, o de la distorsión de las mismas. Frente a este borramiento o representación negativa, la estrategia de los grupos LGTB mainstream es la de demandar representaciones más reales y positivas (cuestión compleja, por cierto, la de qué se considera real y positivo: puede que no todo el mundo comparta la misma opinión). La homofobia sería un problema de ignorancia, de no conocer lesbianas, gays, trans. Al hacerlo, la gente se da cuenta de que son normales, y este es el final feliz de la discriminación. Otra lectura es que, aunque la homofobia no pueda ser erradicada a través de la inclusión de estas (otras) representaciones en el curriculum, al menos estas imágenes ofrecen modelos y autoestima para los estudiantes no heterosexuales (LUHMANN, 1998).

Un debate clave aquí, en relación con el punto anterior, es el que tiene que ver con la visibilidad. Desde los colectivos LGTB (de carácter moderado, identitarios) se defiende la necesidad de salir del armario, de ser visibles, en ocasiones a toda costa. Las teorías queer, por su parte, critican la identidad y, al mismo tiempo, defienden la visibilidad in your face (DE LAURETIS, 1991). En esta línea, podemos plantearnos no salir del armario, o al menos no hacerlo en los términos que se esperan. Personalmente, mi posicionamiento crítico, queer, con la visibilidad puede malinterpretarse como que estoy escondiendo algo (que no es el caso), o que no estoy suficientemente orgullosa o algo por el estilo (tampoco); soy consciente de que esa es otra dificultad también, otro salto (que puede ser mortal) sin red. Uno de los pánicos que, creo, compartimos muchos profesores lesbianas, gays y trans es que te pregunten, en medio de la clase, si eres lesbiana, por ejemplo, y no aciertes a dar la mejor respuesta (difícil hacerlo en clave queer en esa situación, para lo que se necesitaría algo de tiempo), o llegar al centro y encontrarte un grafiti insultante y cosas así.

En este sentido, la crítica central que se ha hecho al discurso de la diversidad es que no supone un cambio estructural (TALBURT, 2005), dejando la (hetero) norma intacta. Se trata de un discurso de corte liberal sobre las minorías sexuales, que tienen necesidades especiales $\mathrm{y}$ requieren atención específica, ayuda $\mathrm{y}$ tolerancia, en el marco de la igualdad. Una de las ideas que aparece de manera reiterada en este tipo de discurso es la necesidad de normalizar la homosexualidad, que a mí personalmente siempre me ha horrorizado. Esta práctica viene a reforzar al final tanto la propia heterosexualidad como la anormalidad del deseo hacia personas del mismo sexo, es decir, se mantienen los estereotipos, los binarismos, la patologización de la homosexualidad, y la idea de que es un problema personal (QUINLIVAN; TOWN, 1999). Como apunta Rofes (2005, p.158), en su análisis sobre el género, el sexo y los profesores varones gays

[...] hemos ganado un acceso limitado a las aulas a cambio de negar las auténticas diferencias de muchas relaciones de hombres gays con los roles de género, las culturas sexuales y los modos de 
parentesco y aquellos de la hegemonía heteronormativa.

Todas estas cuestiones nos llevan a interrogarnos sobre la política del reconocimiento (ysi es suficiente).Lacentralidad, todavía hoy, de la heteronormatividad dentro de los marcos progresistas (como los discursos de la diversidad) es posible a través de la normalización inclusiva de posicionamientos LGTB como un conjunto de identidades discretas y discernibles que pasan a ser aceptables, siempre y cuando se ajusten a ciertos modos de sujeción relacionados con construcciones sociales claves como la familia y la nación. Las políticas de la diversidad sexual, que muy a menudo contienen una visión idealizada de ésta, se enfrentan al mismo problema que el multiculturalismo, cooptado por la idea implícita de universalidad que clausura todo lo que significa diferencia. Esta perspectiva ha asumido que las diferentes dimensiones de poder operan como un set de diferencias fijas y acumulativas, sin considerar los modos particulares, contradictorios y no analizados en los que esas dimensiones de poder interseccionan. Partiendo de que las aportaciones teóricas queer giran en torno al cuestionamiento de los límites, tenemos que ser conscientes de los peligros de celebrar el reconocimiento sin criticar las asunciones liberales implícitas, y de los límites que cercan el marco epistémico de lo que puede ser conocido, clausurando el análisis acerca de cómo los cuerpos y sus placeres pueden ser pensados (TRUJILLO; SABSAY, 2010).

\section{Potencialidades y retos de una pedagogía queer y feminista}

La pedagogía, cuando va unida a etiquetas como feminista, antirracista, antihomófoba es crítica con la educación mainstream como espacio de reproducción de relaciones de poder desiguales. Al mismo tiempo, queer es una crítica a las prácticas de normalización que se dan en el estudio de la sexualidad. A esta intersección se le ha denominado pedagogía queer, un campo que cuenta ya con cierto desarrollo en los últimos años. En el contexto español, hasta donde yo conozco, no hay muchos trabajos que intenten mirar y pensar el ámbito educativo desde esa encrucijada; los temas de educación se trabajan, en enorme medida (no exentos de dificultades con las instituciones), desde el discurso de la diversidad y la política identitaria LGTB. Los planteamientos queer han perturbado poco (todavía) las teorías y prácticas educativas en España.

Entiendo queer en estas páginas como diferente, inapropiado, insubordinado, raro/a, no normal, no como simplemente alternativo, o como una abreviatura de lesbianas, gays, transexuales, bisexuales, transgéneros e intersexuales. Entonces, y como se pregunta Guacira Lopes Louro (2012), ¿cómo pueden los saberes queer, intrínsecamente subversivos y provocadores, articularse en campos tradicionalmente normalizadores y disciplinadores como la Educación? Queer alude a un conjunto de saberes (más que a un corpus teórico sistematizado y acabado) y a una disposición política. Se trata de un movimiento post- identitario, que mantiene una posición crítica sin negar la labor de los identitarios ni romper con ellos, pero que supone un cambio de mirada, un cambio epistemológico. Las contribuciones queer hacen más hincapié en las prácticas que en las identidades, y cuestionan los binarismos sobre los que se asienta el saber y la cultura dominantes (LOUR0, 2012).

Los saberes queer cuestionan la supuesta coherencia de las identidades gay, lesbiana, transexual, haciéndolas sospechosas, evidenciando y desmantelando los procesos regulatorios de la formación y categorización de los sujetos. Las prácticas, historias y experiencias queer cuestionan los límites de las identidades de género y sexuales, que no son algo homogéneo y fijo, y que están atravesadas por otras (TRUJILLO, 2009). Podemos queerizarlas, o complicarlas (KOPELSON, 2002). En mi clase, por ejemplo, y para evitar ser vista como la 
lesbiana, sin más, les hablo de mi participación en una asamblea del movimiento 15M (también conocido como Spanish revolution), de mi activismo feminista, ecologista, ciclista, del privilegio de ser blanca (del que no nos damos cuenta), etc. Es mi manera de exceder el espacio en el que se me sitúa, desbordándolo con una lista de otras categorías. Más que analizar $\mathrm{y}$ representar a sujetos out and proud, una pedagogía queer persigue, sin desmerecer a los anteriores, la proliferación infinita de nuevas identificaciones. 0, como apunta Kopelson, "hacer visible algo que todavía no hemos visto" (2002, p. 30).

En la búsqueda de respuestas a estas preguntas e inquietudes, de carácter individual y colectivo, las lecturas y prácticas políticas queer, postmodernas $\mathrm{y}$ feministas han significado contar con una muy buena caja de herramientas para analizar, de otra manera, qué entendemos acerca del género, la sexualidad, la identidad, el discurso, y el cuerpo. Nos ofrecen una aportación crucial sobre la construcción de la subjetividad y el deseo. En los últimos años, han significado un giro copernicano en nuestra manera de pensar, de movilizarnos, de investigar y enseñar: hemos pasado del discurso de las minorías sexuales (política identitaria) a los discursos universalizadores (SEDGWICK, 1990). Como he comentado más arriba en este artículo, la heteronormatividad no sólo afecta a gays, lesbianas y trans, y lo mismo es aplicable a otros vectores de opresión como el género o la raza.

Queer hay que entenderlo como un adjetivo y como movimiento, acción, como un verbo: queerizar la escuela, la clase, el conocimiento, las metodologías (y los movimientos sociales, el espacio público y un largo etcétera). Una pedagogía queer, como apunta Luhman (1998) debería ir más allá de la incorporación del contenido queer en los currícula y de la preocupación sobre la búsqueda de estrategias de enseñanza que hagan ese contenido más accesible para el alumnado; y escribo esto sin dejar de pensar que muchas veces resulta inevitable moverse entre la urgencia de la práctica cotidiana (¿pero cómo llevamos todo esto al aula?) y el análisis y la reflexión.

En relación con esta última, los puntos centrales a la hora de queerizar la educación serían el cuestionamiento de la normalidad, la disolución de los binarismos, y la formación de alianzas, de redes (QUINLIVAN; TOWN, 1999). Si la pedagogía queer está comprometida con la práctica radical de deconstruir la normalidad, esto significa que no puede necesariamente reducirse a enseñar para o sobre sujetos queer (BRITZMAN, 1995). Además, el rechazo a cualquier normalización, sea racista, sexista o la que sea, tiene que ser parte de esa agenda queer. Retomando el video de Vestido nuevo, materiales como este pueden servirnos para pensar la diferencia y la normalidad, y para preguntarnos cómo la normalidad y la anormalidad pasan a ser posiciones asignadas al sujeto, y cómo pueden ser subvertidas. Como nos recuerda Luhmann (1998), una mirada queer transgrede precisamente los límites entre lo queer y lo normal (heterosexual): por un lado, al descifrar los contenidos y subtextos queer en las narrativas heterosexuales, y, por otro, al apuntar el solapamiento entre las prácticas homosexuales y las heterosexuales. Las teorizaciones queer insisten en que las sexualidades no heterosexuales son simultáneamente marginales y centrales, y que la norma heterosexual necesita de la desviación homosexual para existir.

Esta batalla por derribar los binarismos, mujer-hombre, homosexual-heterosexual es otro de los puntos clave. La diferencia, como señaló Fuss (1991), es la condición necesaria para la identidad. Foucault ya argumentó en su Historia de la sexualidad (1978) que la construcción del sujeto burgués está basada en la contraposición heterosexual-homosexual. La heterosexualidad como régimen político se refuerza a través de las múltiples violencias homófobas, de las desigualdades de tipo social y legal, y de los gestos de tolerancia a lesbianas y gays, diferentes 
pero iguales. Para Fuss, queer, como término, señala no sólo la perturbación de la normalidad heterosexual por un lado, y el desafío por otro, sino que persigue "llevar la oposición hetero/ homo al punto del colapso" (1990, p. 1).

Los saberes queer resisten ante el deseo de autoridad y de certezas definitivas, ante un conocimiento sin contradicciones, sin dudas. La educación es mucho más que transmitir conocimientos: tiene que ver con la creación de una nueva condición de conocimiento, de una disposición de aprendizaje original, diferente. Aprender sobre el contenido es diferente a aprender desde él, engloba el proceso menos predecible y más lioso de pasar a estar implicadx en el conocimiento (LUHMANN, 1998). Queer, en definitiva, es "una manera de conocer, más que algo a ser conocido" (KOPELSON, 2002, p. 25) ${ }^{9}$.

$Y$ al hilo de la cuestión de la duda metodológica, retomo las cuestiones que planteaba al comienzo. Cómo trabajar desde una pedagogía queer cuando no ha habido, ni hay, un recorrido sobre temas de sexualidad, LGTBI, y mucho menos queer. En mi caso, y el de tantos docentes, intentar queerizar la educación sin estudios sobre géneros y sexualidades, feministas y LGTBI previos (ni existentes en la actualidad en los Grados, como expliqué al inicio) es todo un reto; 0 tal vez, no sea necesario pasar por esa fase para plantear cuestiones queer, y que en estos contextos de ausencias pueda ser, paradójicamente, más fácil comenzar a hablar de ciertos temas, desde esa otra mirada, queer, sin tener que batallar contra un corpus de estudios ya más institucionalizado. En relación con este punto, me parece interesante la propuesta que hace Karen Kopelson (2002), de una combinación de ambas, la política identitaria y la pedagogía queer, como manera -también- de huir de la lógica (binaria) de la una en oposición a la otra. En realidad, esto es lo que puede suceder (y sucede) en muchos centros escolares, que la política identitaria y las prácticas y saberes queer se trabajen en paralelo. Susan Talburt (2005 apud

9- Mi traducción del original en inglés.
KOPELSON, 2002), nos advierte, refiriéndose al contexto estadounidense, que la identidad, la voz y la visibilidad, continúan, pese a todos los retos postestructurales, manteniéndose en los enfoques del trabajo académico de y sobre lesbianas, gays y trans a través de numerosas disciplinas. Y, finalmente, no está de más señalar, asimismo, que las prácticas transgresoras $\mathrm{y}$ subversivas también pueden obviamente tener límites, como todas las propuestas.

El reto es, en definitiva, cómo incorporar las aportaciones queer a nuestra práctica educativa, al tiempo que esta misma nos hace reflexionar sobre las cuestiones centrales de las teorías queer. En un contexto en el que todavía nos encontramos con muchas dificultades y hostilidades de varios tipos (entre ellas, institucionales) hacia todos estos temas, creo que es necesario y urgente seguir incidiendo en la necesidad de formación del profesorado y el trabajo en red(es); en muchas ocasiones estamos bastante solxs en nuestros centros educativos y creo que es fundamental el apoyo, la colaboración, la puesta en marcha de proyectos, compartir experiencias e ideas, sumar energías colectivamente, en definitiva. Lxs docentes, aquí sin duda, no podemos esperar a que los cambios nos vengan de la mano de las políticas públicas o de las leyes y proyectos educativos para actuar. La escuela no sólo debería ir en paralelo a las problemáticas y retos de la realidad social, sino que deberíamos adelantarnos, y ser uno de los espacios que liderara el cambio político y social, el pensamiento crítico.

$\mathrm{Si}$ queremos despatriarcalizar, desracializar y desheterosexualizar la educación me parece que la pedagogía queer es un horizonte interesante a perseguir: una invitación a no pensar straight, a pensar desde otro lugar. En defınitiva, ¿por qué son tan incómodos los cuerpos, los deseos y las sexualidades no heteronormativas en educación? Porque cuestionan todo el andamiaje. ¿Y si, entonces, se entendieran como una manera de repensar, de replantear las bases sobre las que hemos construido el conocimiento y la educación? 


\section{Referencias}

BORRILLO, Daniel. Homofobia. Barcelona: Bellaterra, 2001.

BRITZMAN, Deborah. Is there a queer pedagogy. Or, stop reading straight. Educational Theory, Illinois, n. 45, p. 151- $165,1995$.

BUTLER, Judith. Cuerpos que importan: sobre los límites materiales y discursivos del "sexo". Buenos Aires: Paidós Ibérica, 2002.

DE LAURETIS, Queer theory: lesbian and gay sexualities. Differences: A Journal of Feminist Cultural Studies, Durham, v. 2, n. 3, p. 3-18, 1991.

ESPAÑA. Ley de ordenación general de sistema educativo. Boletín Oficial del Estado. Ley 1 de 3 de octubre de 1990. Disponible en: <http://www.boe.es/buscar/doc.php?id=BOE-A-1990-24172>. Acceso en: 2014.

ESPAÑA. Ley orgánica de educación. Boletín Oficial del Estado. Ley 2 de 3 de mayo de 2006. Disponible en: <http://www.boe. es/boe/dias/2006/05/04/pdfs/A17158-17207.pdf>. Acceso en: 2014.

ESPAÑA. Ley orgánica para la mejora de la calidad educativa. Boletín Oficial del Estado. Ley 8 de 9 de diciembre de 2013. Disponible en: <http://www.boe.es/boe/dias/2013/12/10/pdfs/BOE-A-2013-12886.pdf>. Acceso en: 2014.

FERRARI, Anderson. Hacer investigación con jóvenes en los colectivos gays. In: Jornadas Investigar con los jóvenes: cuestiones temáticas, metodológicas, éticas y educativas, 1., 2011, Barcelona. I Jornadas... Barcelona: [s.n.], 2011.

FOUCAULT, Michel. Historia de la sexualidad I: la voluntad de saber. Madrid: Siglo XXI, 1978.

FUSS, Diana (Ed.). Inside/out: lesbian theories, gay theories. New York: Routledge, 1991.

HOOKS, Bell. Teaching to transgress: education as the practice of freedom. New York: Routledge, 1994.

ERIBON, Didier. Reflexiones sobre la cuestión gay. Barcelona: Anagrama, 2001.

KOPLESON, Karen. Dis/integrating the gay/queer binary: "reconstructed identity politics" for a performative pedagogy. College English, Illinois, v. 65, n. 1, p. 17-34, 2002.

LOURO, Guacira Lopes. Gênero, sexualidade e educação: uma perspectiva pós- estruturalista. Petrópolis: Editora Vozes, 1997.

LOURO, Guacira Lopes (Coord.). 0 corpo educado: pedagogias da sexualidade. Belo Horizonte: Autêntica, 2000.

LOURO, Guacira Lopes. Os estudos queere a educação no Brasil: articulações, tensões, resistências. Contemporánea, São Carlos, v. 2, n. 2, p. 363-369, 2012.

LUHMANN, Susanne. Queering/querying pedagogy? Or, pedagogy is a pretty queer thing. In: PINAR, William F. Queer theory in education. Mahwah: Lawrence Erlbaum, 1998. p. 120-132.

MOITA, Luiz Paulo. Sexualidades em sala de aula: discurso, desejo e teoria queer. In: MOREIRA, Antônio Flávio Barbosa; CANDAU, Vera Maria (Coords.). Multiculturalismo: diferenças culturais e práticas pedagógicas. Petrópolis: Vozes, 2008. p. 125-148.

QUINLIVAN, Kathleen; TOWN, Shane. Queer pedagogy, educational practice and lesbian and gay youth. International Journal of Qualitative Studies in Education, Abgindon, v. 12, n. 5, p. 509-524, 1999.

ROFES, Eric. La transgresión y el cuerpo ubicado: el género, el sexo y los profesores varones gays. In: TALBURT, Susan; STEINBERG, Shirley (Eds.). Pensando queer. sexualidad, cultura y educación. Barcelona: Graó, 2005. p. 141-157.

RUBIN, Gayle. Thinking sex: notes for a radical theory of the politics of sexuality. In: VANCE, Carole (Ed.). Pleasure and danger: exploring female sexuality. Boston: Routledge, 1984. p. 267- 319.

SÁNCHEZ, Mercedes. Cómo educar en la diversidad afectiva, sexual y personal en educación infantil: orientaciones prácticas. Madrid: La Catarata, 2009. 
SÁNCHEZ, Mercedes (Coord.). Cómo educar en la diversidad afectiva, sexual y personal en los centros escolares: orientaciones prácticas para la ESO. Madrid: La Catarata, 2010.

SEDGWICK, Eve. Epistemology of the closet. Berkeley: University of California Press, 1990.

TALBURT, Susan. 2005. Política de identidad, respuesta institucional y negociación cultural: significados de la creación de una oficina universitaria de gays y lesbiana. In: TALBURT, Susan; STEINBERG, Shirley (Eds.). Pensando queer: sexualidad, cultura y educación. Barcelona: Graó, 2005. p. 77-98.

TRUJILLO, Gracia. Del sujeto político la mujer a la agencia de las (otras) mujeres: el impacto de la crítica queer en el feminismo del estado español. Política y Sociedad, Madrid, v. 46, n. 1/2, p. 161- 172, 2009.

TRUJILLO, Gracia. Sexismo, racismo y xenofobia: la educación como ámbito privilegiado para su prevención. In: RODRIGUEZ YAGÜE, Cristina (Ed.). Estudios sobre género y extranjería. Albacete: Bomarzo, 2011. p. 47-60.

TRUJILLO, Gracia; SABSAY, Leticia. Discourses on diversity: silences and phantasms in education. In: GEA Interim Conference, Gender and Education. Diversity of Voices, 2010, Barcelona. Gender... Barcelona: Universidad de Barcelona, 2010.

WARNER, Michael. Fear of a queer planet: queer politics and social theory. Minneapolis: University of Minnesota Press, 1993.

WEEKS, Jeffrey. El malestar de la sexualidad. Madrid: Talasa, 1992.

Recebido en: 06.11.2014

Aprobado en: 02.03.2015

Gracia Trujillo es doctora en sociología, profesora de sociología en la Universidad de Castilla- La Mancha, España (UCLM) y activista, interesada en las teorías y prácticas feministas queer, la política sexual y la educación, ámbitos en los que cuenta con un número amplio de publicaciones. Ha formado parte de diferentes proyectos de investigación en este campo y ha sido investigadora invitada en diversas universidades, como la NYU, la UBA, Coimbra y Flacso- Quito, entre otras. 